\title{
Evidence for the Existence of Two Homoserine Dehydrogenases in Serratia marcescens
}

\author{
By S. KOMATSUBARA, * M. KISUMI AND I. CHIBATA \\ Research Laboratory of Applied Biochemistry, Tanabe Seiyaku Co. Ltd., Kashima, \\ Yodogawa-ku, Osaka 532, Japan
}

(Received 26 May 1983)

\begin{abstract}
Strain D-315 was isolated from a wild-type strain of Serratia marcescens as a methioninesensitive mutant. In this mutant, methionine-mediated growth inhibition was reversed by threonine or homoserine. The homoserine dehydrogenase activity of strain D-315 was about $20 \%$ lower than that of the wild-type and was not inhibited by threonine. The methioninesensitive mutation was located in the $t h r$ region on the chromosome, indicating that strain D-315 lacked homoserine dehydrogenase I, whose activity is inhibited by threonine and whose synthesis is multivalently repressed by threonine plus isoleucine. In a methionine bradytroph derived from strain D-315, homoserine dehydrogenase activity was high during growth in the absence of methionine and low during growth in the presence of excess methionine. Strain D413 , a homoserine auxotroph derived from strain D-315, had no detectable homoserine dehydrogenase activity, indicating that $S$. marcescens had homoserine dehydrogenase II, whose synthesis is controlled by methionine-mediated repression. The gene coding for homoserine dehydrogenase II was located in the metB-argE region. Strain TA-191, having homoserine dehydrogenase I and lacking the other isoenzyme, was constructed by transduction. This strain was sensitive to threonine-mediated growth inhibition.
\end{abstract}

\section{INTRODUCTION}

In micro-organisms, homoserine dehydrogenase (EC 1.1.1.3) catalyses the formation of homoserine from aspartate- $\beta$-semialdehyde and is one of the rate-limiting enzymes for the biosynthesis of threonine, isoleucine and methionine (Fig. 1) (Umbarger, 1978). Escherichia coli K12 and Salmonella typhimurium have two homoserine dehydrogenase isoenzymes (Cohen, 1969). The synthesis of homoserine dehydrogenase I is multivalently repressed by threonine plus isoleucine and its activity is subject to feedback inhibition by threonine. The synthesis of homoserine dehydrogenase II is repressed by methionine but it is not subject to feedback inhibition by any related end-product. Therefore, these enzymes are often called threoninesensitive homoserine dehydrogenase and methionine-repressible homoserine dehydrogenase, respectively.

We have been studying threonine production by various regulatory mutants of Serratia marcescens Sr41 and have shown alterations in feedback controls of threonine biosynthesis in these mutants (Komatsubara et al., 1978a, b, 1979a,b). However, it has not been clear whether $S$. marcescens might have two homoserine dehydrogenase isoenzymes. In this paper, we give genetic evidence for the existence of the two isoenzymes in $S$. marcescens.

\section{METHODS}

Bacterial strains. Derivatives of S. marcescens Sr41 (Matsumoto et al., 1975) were used (Table 1). The genotype designations used are generally based on those for $E$. coli K12 (Bachmann \& Low, 1980; Thèze et al., 1974; Thèze \& Saint-Girons, 1974). 


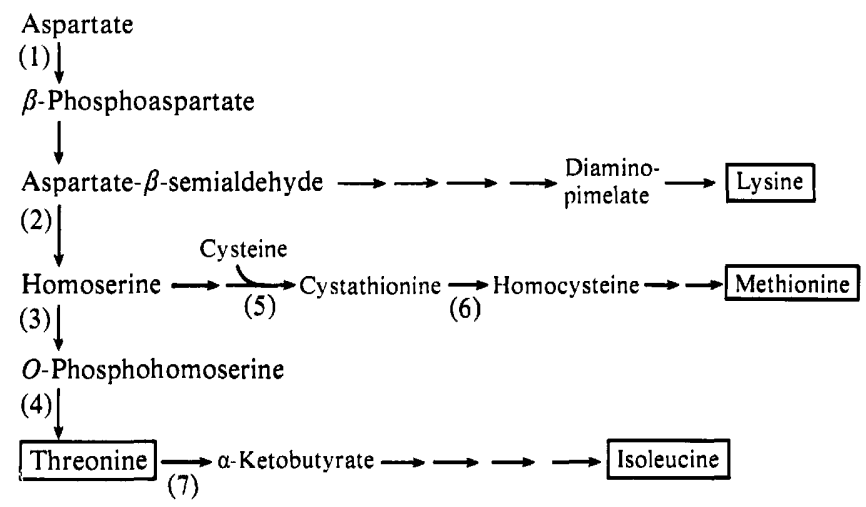

Fig. 1. Pathways for biosynthesis of amino acids of the aspartate family in bacteria. Enzymes: (1) aspartokinase, (2) homoserine dehydrogenase, (3) homoserine kinase, (4) threonine synthase, (5) $\gamma$ cystathionine synthase, (6) $\gamma$-cystathionase, (7) threonine deaminase.

Table 1. S. marcescens Sr41 strains used

\begin{tabular}{|c|c|c|c|}
\hline Strain* & Relevant genotype $†$ & Origin & Reference \\
\hline Mu-910 & Wild-type & Mutagenesis of 8000 & Komatsubara et al. $(1978 b)$ \\
\hline D-43 & $\operatorname{thrB} / C 21$ & Mutagenesis of Mu-910 & This paper \\
\hline D-44 & $\operatorname{thrB} / \mathrm{C} 22$ & Mutagenesis of Mu-910 & This paper \\
\hline D-60 & ilvAI & Mutagenesis of $\mathrm{Mu}-910$ & Komatsubara et al. (1978b) \\
\hline D-315 & thr $\mathrm{A}_{2} 3$ & Mutagenesis of Mu-910 & This paper \\
\hline D-403 & thr $A_{2} 3$ metBll & Mutagenesis of D-315 & This paper \\
\hline D-408 & thr $A_{2} 3$ metCl2 & Mutagenesis of D-315 & This paper \\
\hline D-413 & thr $A_{2} 3$ metMI3 & Mutagenesis of D-315 & This paper \\
\hline D-443 & $\operatorname{thr} \mathrm{A}_{2} 3 \operatorname{argE} 11$ & Mutagenesis of D-315 & This paper \\
\hline TA-191 & $\operatorname{met} M 13$ & Mu-910 phage $\times$ D-413 & This paper \\
\hline
\end{tabular}

* Strain Mu-910 was derived from strain 8000 (wild-type) as a threonine dehydrogenase-deficient strain. Therefore, all strains listed here were deficient in threonine dehydrogenase.

† In $E$. coli K12, the thr $A$ gene specifies a single polypeptide chain (Cohen, 1969) but is composed of two cistrons, $t h r A_{1}$ and $t h r A_{2}$, which correspond to aspartokinase I and homoserine dehydrogenase I, respectively (Thèze \& Saint-Girons, 1974). Also the met $L$ gene codes for a bifunctional enzyme, aspartokinase II-homoserine dehydrogenase II (Dautry-Varsat et al., 1977; Krueger et al., 1981). But here we designate a cistron carrying homoserine dehydrogenase II activity as $m e t M$, according to the classical usage (Thèze et al., 1974; Bachmann \& Low, 1980).

Genotype designations: $\operatorname{thr} A_{2} 3$, lack of homoserine dehydrogenase I (methionine sensitivity); thrB/C21, lack of homoserine kinase or threonine synthase (threonine auxotrophy); $\operatorname{thr} B / C 22$, lesion of homoserine kinase or threonine synthase (threonine bradytrophy); metB 11 , lack of $\gamma$-cystathionine synthase (methionine auxotrophy); metC12, lesion of $\gamma$-cystathionase (methionine bradytrophy); metM13, lack of homoserine dehydrogenase II (homoserine auxotrophy in a $\operatorname{thr} A_{2} 3$ strain or threonine sensitivity in a $\operatorname{thr} A_{2}^{+}$strain); $\arg E 11$, lack of acetylornithine deacetylase (arginine auxotrophy); ilvAl, lack of threonine deaminase (isoleucine auxotrophy).

Media. The medium of Davis \& Mingioli (1950) was modified by omitting citrate and increasing glucose to a final concentration of $0.5 \%(w / v)$. The solution of glucose was autoclaved separately and mixed with the other components.

Isolation of mutants. Cells of parent strains were mutagenized with $N$-methyl- $N^{\prime}$-nitro- $N$-nitrosoguanidine by the method of Adelberg et al. (1965), modified as described previously (Kisumi et al., 1977). Enrichment of auxotrophs or bradytrophs was achieved by nalidixic acid treatment by the procedure of Weiner et al. (1974). Methionine-sensitive mutants were enriched in the presence of $10 \mathrm{mM}-\mathrm{L}$-methionine. The survivors were grown on nutrient agar plates overnight at $30^{\circ} \mathrm{C}$. Subsequently, colonies were replica-plated on to minimal plates with or without the addition of necessary supplements. Colonies showing the expected phenotype were purified by single colony isolation, and characterized for genetic lesions.

Transductional analysis. Phage PS20-mediated transduction was carried out by the method of Matsumoto $e$ al . (1973), modified as described previously (Komatsubara et al., 1979b). In the cross strain D-315 $\times$ strain D-43, 
$\mathrm{Thr}^{+}$transductants were selected on minimal plates and tested for methionine-sensitive phenotype on minimal plates containing $1 \mathrm{mM}-\mathrm{L}-$-methionine. In the crosses strain D-413 $\times$ strain D-443 and strain D-413 $\times$ strain D403, $\mathrm{Arg}^{+}$and $\mathrm{Met}^{+}$transductants were selected on minimal plates containing $0.5 \mathrm{~mm}$-L-homoserine. In the cross strain D-443 $\times$ strain D-403, Met $^{+}$transductants were selected on minimal plates containing 1 mM-L-arginine. For construction of strain TA-191 from strains Mu-910 and D-413, Thr $^{+}$transductants were selected on minimal plates containing $1 \mathrm{mM}$-L-methionine. Plates for transductional crosses were incubated at $30^{\circ} \mathrm{C}$ for 2 or $3 \mathrm{~d}$. Plates for testing phenotypes were incubated at the same temperature overnight.

Growth study. Cell growth at $30^{\circ} \mathrm{C}$ was estimated using a Hitachi automated recording incubator system (Morimoto et al., 1980) as described previously (Komatsubara et al., 1979a).

Enzyme assay. To a $500 \mathrm{ml}$ Sakaguchi shaking flask was added $150 \mathrm{ml}$ of a minimal medium modified by decreasing the glucose concentration to $0.02 \%(w / v)$. When required, amino acids were added to the medium at $0.05 \mathrm{~mm}$. The medium was inoculated with a loopful of cells grown on a nutrient agar slant overnight and incubated at $30^{\circ} \mathrm{C}$ on a reciprocal shaker $\left(140\right.$ r.p.m., $7 \mathrm{~cm}$ stroke). After $16 \mathrm{~h}$, growth ceased at an $\mathrm{OD}_{660}$ of 0.05 to 0.08 (measured in a Hitachi electric photometer, EPO-B type). More glucose and amino acids were then added to give final concentrations of $0.5 \%(w / v)$ and $1 \mathrm{mM}$, respectively. Incubation was continued until the $\mathrm{OD}_{660}$ reached about 0.5 (late exponential phase). Cells were then centrifuged, washed twice with $50 \mathrm{~mm}$-potassium phosphate buffer (pH 8.0) and suspended in the same buffer containing $30 \%(\mathrm{w} / \mathrm{v})$ glycerol for enzyme stabilization. Cells were disrupted at below $10^{\circ} \mathrm{C}$ for $4 \mathrm{~min}$ with a sonic oscillator (Kubota Insonata, model 200M, $9 \mathrm{KHz}, 200 \mathrm{~W}$ ). The sonically treated suspension was centrifuged at $30000 \mathrm{~g}$ for $40 \mathrm{~min}$ at below $5^{\circ} \mathrm{C}$. The supernatant was used for enzyme assays.

The activities of homoserine dehydrogenase and aspartokinase were determined at $30^{\circ} \mathrm{C}$ as described previously (Kisumi et al., 1977). Protein was measured by the Lowry method. Specific activities are expressed as $\mu \mathrm{mol}$ product formed (mg protein) $)^{-1} \mathrm{~min}^{-1}$.

Chemicals. L-Threonine hydroxamate was prepared from L-threonine methylester and hydroxylamine by the synthetic method for serine hydroxamate (Tosa \& Pizer, 1971). L-Isoleucine hydroxamate was obtained from Sigma. L-Homoserine was purchased from Kyowa Hakko Kogyo. The other amino acids, including D-threonine, were products of our company. The other reagents were of reagent grade commercially available.

\section{RESULTS}

Control of homoserine dehydrogenase I synthesis. We have previously shown that $S$. marcescens has homoserine dehydrogenase activity sensitive to threonine-mediated inhibition (Komatsubara et al., 1978a). We have now examined the possibility of multivalent repression by threonine and isoleucine in the control of synthesis of this enzyme.

Strain D-44, a threonine bradytroph, had a higher homoserine dehydrogenase activity than that observed for the wild-type strain when grown in a medium containing excess isoleucine but no threonine (Table 2). Similarly, D-60, an isoleucine auxotroph, had an increased activity when

\section{Table 2. Derepression of homoserine dehydrogenase I by limiting threonine or isoleucine}

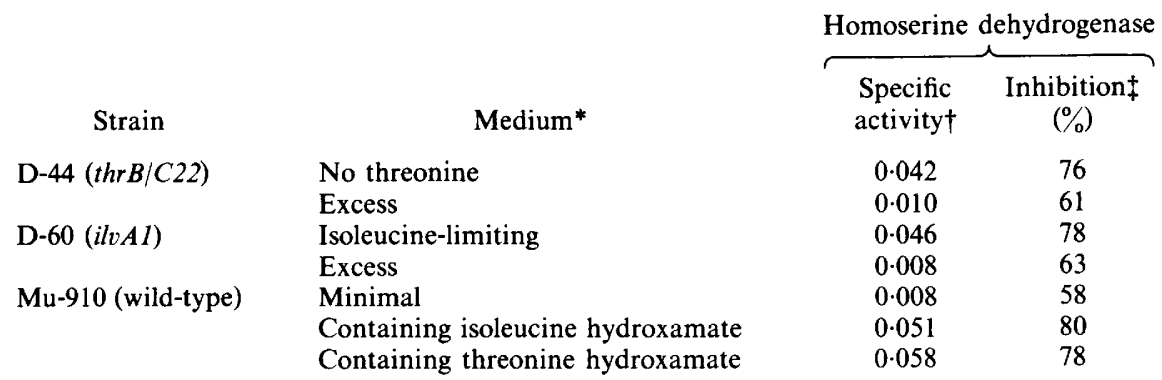

* The media contained the following additions to minimal medium: no threonine medium, $1 \mathrm{~mm}-\mathrm{L}$-isoleucine and no L-threonine; excess medium, $1 \mathrm{mM}$-L-threonine and $1 \mathrm{mM}$-L-isoleucine; isoleucine-limiting medium, $1 \mathrm{mM}$ L-threonine and 0.5 mM-D-threonine (a limiting source of isoleucine; Kisumi et al., 1971); media containing isoleucine hydroxamate or threonine hydroxamate, $2 \mathrm{mM}$-L-isoleucine hydroxamate and $1 \mathrm{~mm}$-L-threonine, or $10 \mathrm{mM}$-L-threonine hydroxamate and $1 \mathrm{mM}-\mathrm{L}$-isoleucine, respectively.

$\dagger$ Expressed as $\mu \mathrm{mol}$ product (mg protein) $)^{-1} \mathrm{~min}^{-1}$.

\$ By $10 \mathrm{~mm}$-L-threonine. 
Table 3. Effect of methionine and related amino acids on the growth rates of strains $\mathrm{Mu}-910$, $D-315$ and $D 413$

\begin{tabular}{|c|c|c|c|}
\hline \multirow[b]{2}{*}{ Addition to minimal medium (mM) } & \multicolumn{3}{|c|}{ Specific growth rate* $\left(\mathrm{h}^{-1}\right)$} \\
\hline & $\mathrm{Mu}-910$ & D-315 & D-413 \\
\hline None & 0.66 & $0 \cdot 39$ & $<0.02$ \\
\hline L-Homoserine $(0.5)$ & 0.51 & 0.60 & $0 \cdot 53$ \\
\hline L-Threonine (1) & 0.65 & 0.63 & $<0.02$ \\
\hline L-Isoleucine (1) & 0.66 & 0.58 & NT \\
\hline L-Methionine $(0 \cdot 01)$ & NT & $0.20-0.39 \dagger$ & NT \\
\hline$(0 \cdot 1)$ & NT. & $0 \cdot 19$ & NT \\
\hline (1) & 0.63 & $0 \cdot 18$ & $<0.02$ \\
\hline L-Methionine (1) + L-homoserine $(0 \cdot 5)$ & NT & 0.69 & NT \\
\hline L-Methionine (1) + L-threonine (1) & NT & 0.63 & 0.69 \\
\hline L-Methionine (1) + L-isoleucine (1) & NT & $0 \cdot 33$ & NT \\
\hline L-Cysteine $(0 \cdot 1)$ & 0.66 & $0.19-0.28 \dagger$ & NT \\
\hline (1) & $0 \cdot 33-0 \cdot 50 \dagger$ & $<0.02$ & NT \\
\hline L-Cysteine $(1)+$ L-homoserine $(0 \cdot 5)$ & $0 \cdot 28-0.50 \dagger$ & $0.36-0.50 \dagger$ & NT \\
\hline L-Cysteine (1) + L-threonine (1) & $0.30-0.53 \dagger$ & $0.35-0.53 \dagger$ & NT \\
\hline
\end{tabular}

cultured in a medium containing excess threonine and a limiting source of isoleucine. The addition of an excess of both threonine and isoleucine lowered the homoserine dehydrogenase activity in the above two strains. In strain $\mathrm{Mu}-910$, the wild-type, the activity was increased by the addition of either threonine hydroxamate (a threonine analogue) or isoleucine hydroxamate (an isoleucine analogue, Kisumi et al., 1971). When an increased activity was obtained, one could consistently observe a higher percentage of inhibition by threonine. On the basis of these results, we concluded that in $S$. marcescens, threonine-sensitive homoserine dehydrogenase was multivalently repressed by threonine and isoleucine. Accordingly, we adopted this enzyme homoserine dehydrogenase I (see Introduction).

Isolation of a methionine-sensitive mutant. In order to show the existence of an isoenzyme distinct from homoserine dehydrogenase $\mathrm{I}$, we intended to isolate a mutant lacking homoserine dehydrogenase I. If $S$. marcescens had no separate isoenzyme, such a mutant would be a homoserine auxotroph. If it had homoserine dehydrogenase II, controlled by methioninemediated repression as in E. coli K12 (Cohen, 1969), the growth of such a mutant would be inhibited by the presence of methionine in the growth medium. Considering these two possibilities, we isolated mutants that did not grow on methionine but did grow on methionine plus threonine. Most of 96 mutants tested grew on threonine but not on homoserine. Three mutants grew slowly in unsupplemented minimal medium and at the normal rate in minimal medium plus homoserine, threonine or isoleucine, as shown for strain D-315 in Table 3. Addition of methionine decreased the growth rate of strain D-315 to half that observed for growth in unsupplemented medium; such inhibition was completely antagonized by homoserine or threonine and partially by isoleucine. Cysteine at $1 \mathrm{mM}$ inhibited the growth of strain D-315 more strongly than methionine.

Homoserine dehydrogenase in a methionine-sensitive mutant. Strain D-315 had a decreased activity of homoserine dehydrogenase (about $20 \%$ of that observed for the wild-type) when grown in minimal medium (Table 4). The aspartokinase activity in strain D-315 was higher than that in the wild-type when both strains were grown in minimal medium. Addition of threonine to the medium lowered the aspartokinase activity in strain D-315. These results indicated that this strain lacked homoserine dehydrogenase I but retained aspartokinase activity that was sensitive to threonine-mediated inhibition.

Mapping of the methionine-sensitive mutation. Transductional analysis was performed to confirm that strain D-315 might have a mutation in the $\operatorname{thr} A_{2}$ gene, specifying homoserine 
Table 4. Homoserine dehydrogenase and aspartokinase activities in strain D-315

\begin{tabular}{|c|c|c|c|c|c|}
\hline \multirow[b]{2}{*}{ Strain } & \multirow[b]{2}{*}{ Addition to minimal medium (mM) } & \multicolumn{2}{|c|}{$\begin{array}{c}\text { Homoserine } \\
\text { dehydrogenase }\end{array}$} & \multicolumn{2}{|c|}{ Aspartokinase } \\
\hline & & $\begin{array}{l}\text { Specific } \\
\text { activity* }\end{array}$ & $\begin{array}{c}\text { Inhibition } \dagger \\
(\%)\end{array}$ & $\begin{array}{l}\text { Specific } \\
\text { activity* }\end{array}$ & $\begin{array}{c}\text { Inhibition } \ddagger \\
(\%)\end{array}$ \\
\hline $\begin{array}{l}\mathrm{Mu}-910 \\
\quad \text { (wild-type) }\end{array}$ & $\begin{array}{l}\text { None } \\
\text { L-Threonine (1) } \\
\text { L-Threonine (1) + L-methionine (1) }\end{array}$ & $\begin{array}{l}0.0078 \\
0.0065 \\
0.0068\end{array}$ & $\begin{array}{l}56 \\
65 \\
59\end{array}$ & $\begin{array}{l}0 \cdot 06 \\
0 \cdot 06 \\
\text { NT }\end{array}$ & $\begin{array}{r}10 \\
8 \\
\mathrm{NT}\end{array}$ \\
\hline $\begin{array}{l}\mathrm{D}-315 \\
\quad\left(\operatorname{thr} A_{2} 3\right)\end{array}$ & $\begin{array}{l}\text { None } \\
\text { L-Threonine (1) } \\
\text { L-Threonine (1) + L-methionine (1) }\end{array}$ & $\begin{array}{l}0.0015 \\
0.0016 \\
0.0010\end{array}$ & $\begin{array}{l}3 \\
5 \\
5\end{array}$ & $\begin{array}{c}0 \cdot 11 \\
0 \cdot 05 \\
\text { NT }\end{array}$ & $\begin{array}{r}47 \\
7 \\
\text { NT }\end{array}$ \\
\hline \multicolumn{6}{|c|}{$\begin{array}{l}\text { NT, Not tested. } \\
\text { * Expressed as } \mu \mathrm{mol} \text { product (mg protein })^{-1} \mathrm{~min}^{-1} \text {. } \\
\dagger \text { By } 10 \mathrm{~mm}-\mathrm{L}-\text {-threonine. } \\
\ddagger \text { By } 50 \mathrm{~mm}-\mathrm{L}-\text { threonine. }\end{array}$} \\
\hline
\end{tabular}

Table 5. Homoserine dehydrogenase activity in derivatives of strain D-315

\begin{tabular}{|c|c|c|c|}
\hline \multirow[b]{2}{*}{ Strain } & \multirow[b]{2}{*}{ Addition to minimal medium (mM) } & \multicolumn{2}{|c|}{$\begin{array}{c}\text { Homoserine } \\
\text { dehydrogenase }\end{array}$} \\
\hline & & $\begin{array}{l}\text { Specific } \\
\text { activity* }\end{array}$ & $\begin{array}{c}\text { Inhibition } \dagger \\
(\%)\end{array}$ \\
\hline \multirow[t]{2}{*}{$\mathrm{D}-408(\operatorname{metC} 12)$} & L-Threonine (1) & 0.0053 & 3 \\
\hline & L-Threonine (1) + L-methionine (1) & 0.0010 & -2 \\
\hline \multirow[t]{2}{*}{ D-413 (metM13) } & L-Homoserine $(0 \cdot 5)$ & 0.0002 & NT \\
\hline & L-Threonine (1) + L-methionine (1) & 0.0002 & NT \\
\hline & $\begin{array}{l}\text { NT, Not tested. } \\
\text { * Expressed as } \mu \text { mol proc } \\
\text { † By } 10 \text { mM-L-threonine. }\end{array}$ & mg prote & $\min ^{-1}$ \\
\hline
\end{tabular}

dehydrogenase I. (For designation of $t h r A_{2}$, see footnote to Table 1.) In the cross between strains D-315 (donor) and D-43 (thrB/C21, recipient), $\mathrm{Thr}^{+}$transductants were obtained. Of $128 \mathrm{Thr}^{+}$ strains, 122 were sensitive to methionine-mediated growth inhibition. This indicated that the mutation leading to loss of homoserine dehydrogenase I activity was located in the thr region on the chromosome. Therefore, we denoted this mutation as $t h r A_{2} 3$.

Evidence for the existence of homoserine dehydrogenase II. The methionine-mediated growth inhibition indicated that $S$. marcescens might have homoserine dehydrogenase II. However, we could not clarify whether the homoserine dehydrogenase remaining in strain D-315 was subject to repression by methionine (Table 4). Therefore, strain D- 408 was derived from strain D-315, as a methionine bradytroph in which the intracellular methionine pool would be limited. This bradytroph had a high homoserine dehydrogenase activity when cultured in minimal medium without methionine and had a lower activity when cultured in minimal medium plus methionine (Table 5). These results indicated that the homoserine dehydrogenase activity remaining in strain D-315 was sensitive to methionine-mediated repression, that is, $S$. marcescens possesses homoserine dehydrogenase II.

Effect of amino acids on the homoserine dehydrogenase II activity. The effect of methionine and related amino acids on the homoserine dehydrogenase II activity was studied with crude extracts of strain D-408 (Table 6; for comparison, data on homoserine dehydrogenase I are given). Methionine, threonine or isoleucine had no effect on the homoserine dehydrogenase II activity at a high concentration. Cysteine inhibited both the homoserine dehydrogenase activities.

Isolation of a mutant lacking both homoserine dehydrogenases. To confirm that homoserine dehydrogenase II might participate in the synthesis of homoserine, we isolated methionine 
Table 6. Effect of amino acids on the activities of the two homoserine dehydrogenases

$\begin{array}{ccc}\begin{array}{c}\text { Addition to reaction } \\ \text { mixture (mM) }\end{array} & \begin{array}{c}\text { Homoserine } \\ \text { dehydrogenase II* }\end{array} & \begin{array}{c}\text { Homoserine } \\ \text { dehydrogenase I† }\end{array} \\ \text { None } & 100(0 \cdot 0055) \ddagger & 100(0 \cdot 031) \ddagger \\ \text { L-Threonine (1) } & \mathrm{NT} & 37 \\ (10) & \mathrm{NT} & 25 \\ (30) & 98 & 19 \\ \text { L-Methionine (30) } & 96 & 96 \\ \text { L-Isoleucine (30) } & 98 & 98 \\ \text { L-Cysteine (1) } & 85 & 70 \\ (10) & 40 & 24 \\ (30) & 32 & 8\end{array}$

NT, Not tested.

* Crude extracts were prepared from cells of strain D-408, grown in a minimal medium and derepressed for homoserine dehydrogenase II.

$\dagger$ Crude extracts were prepared from cells of strain TA-191, grown in a minimal medium and derepressed for homoserine dehydrogenase I.

$\ddagger$ Numbers in parentheses represent specific activities $\left[\mu\right.$ mol product $(\mathrm{mg} \text { protein })^{-1} \mathrm{~min}^{-1}$ ].

Table 7. Transductional analysis of the metM13 mutation

\begin{tabular}{|c|c|c|c|}
\hline Cross* & $\begin{array}{l}\text { Selected } \\
\text { marker } \dagger\end{array}$ & $\begin{array}{c}\text { Unselected } \\
\text { marker } \neq\end{array}$ & $\begin{array}{l}\text { Co-transduction } \\
\text { frequency }(\%)\end{array}$ \\
\hline $\mathrm{e} \times \mathrm{D}$ & $\mathrm{Met}^{+}(146)$ & $\mathrm{Hse}^{-}(141)$ & metB11-metM13 (97) \\
\hline D-413 (metM13) phage $\times$ D-443 (argEII) & $\mathrm{Arg}^{+}(192)$ & $\mathrm{Hse}^{-}(143)$ & metM13-argE11 (74) \\
\hline D-443 $(\arg E 11)$ phage $\times \mathrm{D}-403($ metB Bll $)$ & $\mathrm{Met}^{+}(160)$ & Arg- $^{-}(117)$ & metB11-argE11 (73) \\
\hline
\end{tabular}

* All strains carried the $\operatorname{thr} \mathrm{A}_{2} 3$ mutation.

+ Values in parentheses are the numbers of colonies tested.

$\ddagger$ Values in parentheses are the numbers of colonies found.

auxotrophs from strain D-315 under conditions where the minimal plates contained threonine. Of 23 auxotrophs, two strains, including strain D-413, grew on threonine plus methionine or on homoserine (Table 3). Strain D-413 had no detectable homoserine dehydrogenase activity (Table 5). Accordingly, this strain was considered to lack both homoserine dehydrogenases I and II. The mutation for homoserine dehydrogenase II carried by strain D-413 was designated metM13.

Mapping of the gene coding for homoserine dehydrogenase II. In E. coli $\mathrm{K} 12$, the metM coding for homoserine dehydrogenase II has been mapped between met $B$ and $\arg E$ (Thèze et al., 1974). (For designation of metM, see footnote to Table 1.) Therefore, we examined whether the metM13 mutation might be linked to $m e t B$ and $\arg E$ (Table 7). Strains D-403 and D-443, carrying the metB11 and $\arg E 11$ mutations, respectively, were isolated from strain D-315. In the cross between strains D-413 (donor) and D-403 (recipient), Met $^{+}$transductants were selected on minimal plates containing homoserine. Tests of these $\mathrm{Met}^{+}$strains for homoserine auxotrophy revealed that the metM13 mutation was $97 \%$ cotransducible with met $B^{+}$. In the cross between strains D-443 and D-403, met $B^{+}$was $73 \%$ cotransducible with argE11. These results demonstrated close linkage between the three genes met $B$, met $M$ and $\arg E$.

Construction of a strain having homoserine dehydrogenase I and lacking homoserine dehydrogenase II. To determine the physiological significance of homoserine dehydrogenase II, a strain having homoserine dehydrogenase I and lacking homoserine dehydrogenase II was constructed by transduction. In the cross between strains Mu-910 (thrA $A_{2}^{+}$met $M^{+}$, donor) and D-413 (thr $A_{2} 3$ metM13, recipient), $\mathrm{Thr}^{+}$transductants were selected on minimal plates containing methionine to prevent the appearance of the $m e t M^{+}$colonies. Twenty were tested for growth; all, including 
Table 8. Effect of threonine and related amino acids on the growth rate of strain TA-191

\begin{tabular}{|c|c|}
\hline Addition to minimal medium (mM) & Specific growth rate* $\left(\mathrm{h}^{-1}\right)$ \\
\hline None & 0.63 \\
\hline L-Threonine $(0 \cdot 1)$ & $0 \cdot 33-0.46 \dagger$ \\
\hline (1) & $0 \cdot 22$ \\
\hline (10) & $0 \cdot 12$ \\
\hline L-Threonine $(10)+$ L-homoserine $(0 \cdot 5)$ & 0.65 \\
\hline L-Threonine (10) + L-methionine (1) & 0.69 \\
\hline L-Threonine $(10)+$ L-isoleucine (1) & $0 \cdot 11$ \\
\hline L-Homoserine $(0.5)$ & 0.53 \\
\hline L-Methionine (1) & 0.63 \\
\hline L-Isoleucine (1) & $0 \cdot 66$ \\
\hline
\end{tabular}

strain TA-191, were sensitive to threonine-mediated growth inhibition (Table 8). The growth inhibition was reversed by methionine or homoserine.

The homoserine dehydrogenase activity of strain TA-191 was shown to be inhibited by threonine (Table 6). To confirm the genotype of this strain, a transductional cross was performed between strain TA-191 (donor) and strain D-443 (recipient). About 70\% of $\mathrm{Arg}^{+}$ transductants selected on minimal plates containing homoserine were found to show homoserine auxotrophy. Therefore, the genotype of strain TA-191 is $t h r A_{2}^{+}$metMI3; that is, this strain has homoserine dehydrogenase I and lacks homoserine dehydrogenase II.

\section{DISCUSSION}

In bacteria, the common pathway for biosynthesis of amino acids of the aspartate family has two branched points; aspartate- $\beta$-semialdehyde and homoserine. Homoserine leads to the three end-products threonine, isoleucine and methionine. The regulation of homoserine synthesis depends mainly on feedback controls of homoserine dehydrogenase and aspartokinase activities. On the basis of the results obtained for $E$. coli and Salmonella typhimurium (Cohen, 1969; Umbarger, 1978), enteric bacteria have been thought to possess two homoserine dehydrogenase isoenzymes (Cohen et al., 1969). However, there have been few reports on the existence of the two isoenzymes in enteric bacteria other than the above two species. In this paper, we have demonstrated that Serratia marcescens $\mathrm{Sr} 41$ has homoserine dehydrogenases I and II and that the genetic organization of these regions of the genome of $S$. marcescens is very similar to that in E. coli K12 and Salmonella typhimurium.

In $E$. coli $\mathrm{K} 12$, the growth of the wild-type was reported to be inhibited by threonine in the presence of isoleucine, due to limitation of methionine synthesis by feedback controls of homoserine dehydrogenase I (Patte et al., 1966). This indicates that, in this bacterium, homoserine dehydrogenase II plays a minor role in homoserine synthesis under ordinary conditions. In $S$. marcescens, threonine did not inhibit the growth of the wild-type in the presence of isoleucine but it markedly inhibited that of a strain lacking homoserine dehydrogenase II. This indicates that homoserine dehydrogenase II of $S$. marcescens is more involved in homoserine synthesis than that of $E$. coli K12.

Salmonella typhimurium also has both isoenzymes (Umbarger, 1978); in the wild-type the homoserine dehydrogenase II activity is 20 to $30 \%$ of the total homoserine dehydrogenase activity (Cafferata \& Freundlich, 1970). A mutation causing a lack of homoserine dehydrogenase I was reported to lead to an absolute requirement for threonine (Stuttard, 1973), presumably due to preferential utilization of homoserine produced by homoserine dehydrogenase II for methionine biosynthesis (channelling of homoserine; Cafferata \& Freundlich, 1970). In S. marcescens, homoserine dehydrogenase II activity was inferred to be about $20 \%$ of the total activity. However, in contrast with the case of Salmonella typhimurium, a mutation causing a lack of homoserine dehydrogenase I led to only a slight threonine requirement in the 
absence of methionine and to an increased threonine requirement in the presence of methionine. An $S$. marcescens strain carrying such a mutation did not require methionine for growth in the presence of threonine and its homoserine dehydrogenase II was repressed, indicating that this mutant synthesizes sufficient methionine for growth. Thus, $S$. marcescens differs from Salmonella typhimurium in the channelling of homoserine.

In $S$. marcescens, strain D-315, having only homoserine dehydrogenase II, was more sensitive to cysteine-mediated growth inhibition than the wild-type. We consider that this growth inhibition could be partly due to the inhibition of homoserine dehydrogenase activity. However, the growth inhibition obtained by a high concentration of cysteine was only partially reversed by threonine plus methionine, indicating that homoserine dehydrogenase is not the sole site of the cysteine action (Berglin et al., 1982; Harris, 1981; Kari et al., 1971).

As described above, $S$. marcescens has two homoserine dehydrogenases. Recently, through a strategy similar to that employed in this study, we obtained evidence for the existence of three isoenzymes of aspartokinase, another rate-limiting enzyme for biosynthesis of amino acids of the aspartate family (unpublished results). These recent findings, along with the above results, should make it easy to construct $S$. marcescens strains producing extremely large amounts of threonine, isoleucine, methionine and lysine.

We thank F. Murakami and S. Shindo for technical assistance.

\section{REFERENCES}

Adelberg, E. A., Mandel, M. \& Chein Chin Chen, G. (1965). Optimal conditions for mutagenesis by $N$ methyl- $N^{\prime}$-nitro- $N$-nitrosoguanidine in Escherichia coli K-12. Biochemical and Biophysical Research Communications 18, 788-795.

BachmanN, B. J. \& Low, K. B. (1980). Linkage map of Escherichia coli K-12, edition 6. Microbiological Reviews 44, 1-56.

Berglin, E. H., Edlund, M.-B. K., NyberG, G. K. \& CARLSSON, J. (1982). Potentiation by L-cysteine of the bactericidal effect of hydrogen peroxide in Escherichia coli. Journal of Bacteriology 152, 81-88.

Cafferata, R. J. \& Freundlich, M. (1970). Evidence for channeling of homoserine in Salmonella typhimurium. Biochimica et biophysica acta 222, 671-674.

CoHEN, G. N. (1969). The aspartokinases and homoserine dehydrogenases of Escherichia coli. Current Topics of Cellular Regulation 1, 183-231.

Cohen, G. N., Stanier, R. Y. \& Le Bras, G. (1969). Regulation of the biosynthesis of amino acids of the aspartate family in coliform bacteria and pseudomonads. Journal of Bacteriology 99, 791-801.

Dautry-Varsat, A., Sibilli-Weil, L. \& Cohen, G. N. (1977). Subunit structure of the methionine repressible aspartokinase II-homoserine dehydrogenase II from Escherichia coli K-12. European Journal of Biochemistry 76, 1-6.

Davis, B. D. \& Mingioli, E. S. (1950). Mutants of Escherichia coli requiring methionine or vitamin $\mathrm{B}_{12}$. Journal of Bacteriology 60, 17-28.

HARRIS, C. L. (1981). Cysteine and growth inhibition of Escherichia coli: threonine deaminase as the target enzyme. Journal of Bacteriology 145, 1031-1035.

Kari, C., Nagy, A., Kovacs, P. \& Hernadi, F. (1971). Mechanism of the growth inhibitory effect of cysteine on Escherichia coli. Journal of General Microbiology 68, 349-356.

Kisumi, M., Komatsubara, S., Sugiura, M. \& Chibata, I. (1971). Isoleucine hydroxamate, an isoleucine antagonist. Journal of Bacteriology 107 , 741-745.

Kisumi, M., Komatsubara, S. \& Chibata, I. (1977). Enhancement of isoleucine hydroxamate-mediated growth inhibition and improvement of isoleucineproducing strains of Serratia marcescens. Applied and Environmental Microbiology 34, 647-653.

Komatsubara, S., Kisumi, M., Murata, K. \& Chibara, I. (1978a). Threonine production by regulatory mutants of Serratia marcescens. Applied and Environmental Microbiology 35, 834-840.

Komatsubara, S., Murata, K., Kisumi, M. \& Chibata, I. (1978b). Threonine degradation by Serratia marcestens. Journal of Bacteriology 135, 318323.

Komatsubara, S., Kisumi, M. \& Chibata, I. (1979a). Participation of lysine-sensitive aspartokinase in threonine production by $S$-2-aminoethylcysteineresistant mutants of Serratia marcescens. Applied and Environmental Microbiology 38, 777-782.

Komatsubara, S., Kisumi, M. \& Chibata, I. (1979b). Transductional construction of a threonine-producing strain of Serratia marcescens. Applied and Environmental Microbiology 35, 1045-1051.

Krueger, J. H., Johnson, J. R., Greene, R. C. \& DRESSER, M. (1981). Structural studies of lambda transducing bacteriophage carrying bacterial deoxyribonucleic acid from the metBJLF region of the Escherichia coli chromosome. Journal of Bacteriology 147, 612-621.

Matsumoto, H., TAZaki, T. \& Hosogaya, S. (1973). A generalized transducing phage of Serratia marcescens. Japanese Journal of Microbiology 17, 473479.

Matsumoto, H., Hosogaya, S., SuzuKi, K. \& TAZaKI, T. (1975). Arginine gene cluster of Serratia marcescens. Japanese Journal of Microbiology 19, 35-44.

Morimoto, T., Itoh, H. \& ChibaTA, I. (1980). An automated recording incubator for tube culture of 
microorganisms. Enzyme and Microbiological Technology 2, 194-200.

Patte, J. C., Truffa-Bachi, P. \& Cohen, G. N. (1966). The threonine-sensitive homoserine dehydrogenase and aspartokinase activities of $E s^{-}$ cherichia coli. I. Evidence that the two activities are carried by a single protein. Biochimica et biophysica acta 128, 426 439 .

STUTTARD, C. (1973). Genetic analysis of $t h r$ mutations in Salmonella typhimurium. Journal of Bacteriology 116, $1-11$.

ThÈze, J. \& SaInT-Girons, I. (1974). Threonine locus of Escherichia coli K-12: genetic structure and evidence for an operon. Journal of Bacteriology 118, 990-998.
Thèze, J., Margarita, D., Cohen, G. N., Borne, F. \& PATTE, J. C. (1974). Mapping of the structural genes of the three aspartokinases and the two homoserine dehydrogenases of Escherichia coli K-12. Journal of Bacteriology 117, 133-143.

Tosa, T. \& PIzer, L. I. (1971). Effect of serine hydroxamate on the growth of Escherichia coli. Journal of Bacteriology 106, 966-971.

UMBARgER, H. E. (1978). Amino acid biosynthesis and its regulation. Annual Review of Biochemistry 47, 533606.

Weiner, R. M., Voll, M. J. \& CoOK, T. M. (1974). Nalidixic acid for enrichment of auxotrophs in cultures of Salmonella typhimurium. Applied Microbiology 28, 579-581. 